\title{
Mycophenolate mofetil embryopathy
}

INSERM

\section{Source}

INSERM. (1999). Orphanet: an online rare disease and orphan drug data base.

Mycophenolate mofetil embryopathy. ORPHA:268249

Mycophenolate mofetil (MMF) embryopathy is a malformative syndrome due to the teratogenic effect of MMF, an effective immunosuppressive agent widely used for the prevention of organ rejection after organ transplantation. 